\title{
Determinants of Rural Out-Migration in Habru District of Northeast Ethiopia
}

\author{
Beneberu Assefa Wondimagegnhu' ${ }^{1}$ and Mesfin Eshetu Zeleke ${ }^{2}$ \\ ${ }^{1}$ Department of Rural Development and Agricultural Extension, College of Agriculture and Environmental Sciences, \\ Bahir Dar University, P.O. Box 2289, Bahir Dar, Ethiopia \\ ${ }^{2}$ Save the Children International, Ethiopia Branch, Addis Ababa, Ethiopia \\ Correspondence should be addressed to Beneberu Assefa Wondimagegnhu; benassefa2006@gmail.com
}

Received 19 October 2016; Revised 16 January 2017; Accepted 20 February 2017; Published 14 March 2017

Academic Editor: Christos Tsadilas

Copyright (c) 2017 Beneberu Assefa Wondimagegnhu and Mesfin Eshetu Zeleke. This is an open access article distributed under the Creative Commons Attribution License, which permits unrestricted use, distribution, and reproduction in any medium, provided the original work is properly cited.

Migration has become a cause of concern at the global, regional, and national levels. Like the case of many developing countries, Ethiopia has been facing increasing challenges related to rural out-migration. This study aimed to analyze factors that determine rural communities' decision to migrate to internal and international destinations in Habru district of Northeast Ethiopia. Stratified sampling technique has been employed to select a total of 200 household heads in three agroecologies of the study area. Structured questionnaires have been used as a principal primary data collection method and logistic regression has been employed for analysis. The results of the study showed that intravillage conflict, absence of relief assistant, livestock ownership, farm land size, access to information, and household and individual characteristics including family size, sex, and age of the migrants are the dominant determinant factors for rural out-migration. Migration can have a positive outcome in improving livelihoods if comprehensive and holistic policies and strategies are in place. There is also a need to strengthen the link between rural development policy and the disadvantaged groups by designing and implementing different livelihood alternatives including reducing pressure on scarce resources particularly land, integrating health and education services, and creating nonfarm employment opportunities.

\section{Introduction}

International migration in the horn of Africa has been extensive in the past decades. While international migration has received more attention at this time on migration, internal migration is far more significant in terms of the numbers of people involved and perhaps even the quantum of remittances and its potential for poverty reduction [1]. Sub-Saharan Africa has experienced a noticeable increasing rate of migration in recent years [2]. The increment in the rate of migration is associated with so many interrelated factors that determine the decision to move. Greenwood [3] pointed out that some of the responsible factors for migration are classified based on regional differences between sending and receiving regions and on individual characteristics of migrants. In the same line, Naude [2] and Ivan [4] classified the determinants that affect the migration decision of individuals and families in sub-Saharan Africa as economic determinants, demographic determinants, gravity variables, labour market determinants, conflict, and environmental determinants. Climate variation has been responsible for a displacement of 2.55 million people over the period of 1960-2000 in sub-Saharan Africa (Marchiori et al.) [5]. The problem is particularly severe for countries that depend on the agriculture sector and these have led to rural outmigration as well as shift from agricultural to nonagricultural sector [6]. Similarly, a survey conducted in Burundi, Ghana, Kenya, Mali, Nigeria, Senegal, Togo, and Uganda has considered education, marital status, age, ethnicity, and number of births as determinates of rural out-migration [7]. The survey also indicated that poor economic opportunities of rural areas have been a considerable factor for out-migration taking into account the case of Northern Ghana where migration towards the prosperous coastal towns is prevalent.

Ethiopia experiences many types of migration and it has been both a major origin country for both regular and irregular 


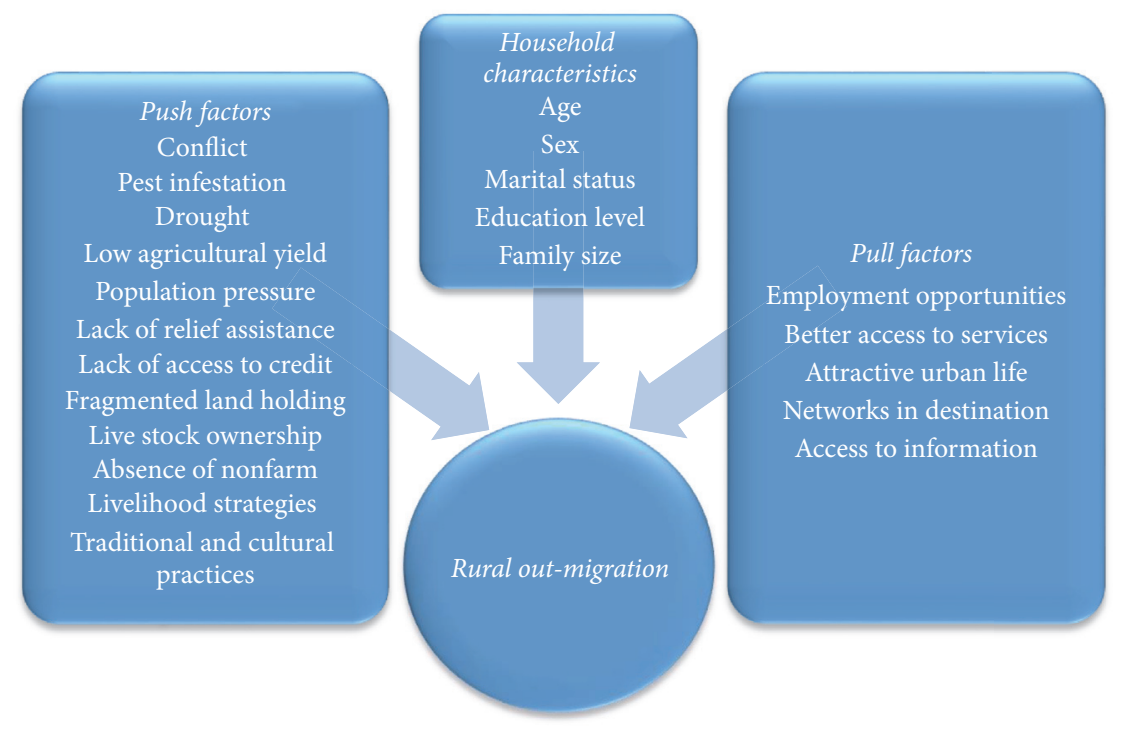

FIGURE 1: Factors determining migration decision (enriched from [10]).

migrants and a destination and transit country mostly for shelter seekers and refugees. One of the main routes used by irregular Ethiopian migrants is the Eastern one. The Eastern migratory route leads to Saudi Arabia, also a major destination country for regular migrants from Ethiopia. The problem of rural out-migration is a raising issue in the country at this time and has been attracting the focus of governmental, nongovernmental, national, regional, and international agencies. Therefore, this study attempts to fill the knowledge gap on the determinants of rural out-migration to different internal and international destinations especially for youth migrants in Ethiopia. This helps to explore experiences for future interventions in addressing the issue of migration as a development agenda. Specifically, this study identifies key determinant factors of out-migration and estimates the magnitude and trend of out-migration in Habru district of Northeast Ethiopia. In addition, the main livelihood strategies of the rural households left behind are examined.

\section{Research Question}

The main research question of the study is

what are the main determinants of rural out-migration in Habru district of Northeast Ethiopia?

\section{Conceptual Framework}

Out-migration is a combination of different factors including push-pull factors, socioeconomic and institutional factors, and household characteristics as illustrated in Figure 1.

\section{Material and Methods}

The case study was conducted in 2015 in Habru district, about $490 \mathrm{kms}$ Northeast of Addis Ababa, the capital of Ethiopia (refer to Figure 2). The research area is purposefully selected because migration is one of the most important livelihood strategies of the local people in the area. This is due to the fact that the area is one of the most drought-prone and food insecure districts in the region, and thus local people have been seasonally or permanently migrating to different places of the country and abroad. 200 households were selected by systematic random sampling method representing a total of 2473 households. According to Neuman [8], random sample drawing does not only help to depict the target population with sufficient accuracy but also enable the researcher to establish a statistical relationship between the sample and the population. Both primary and secondary data were collected. Primary data were collected from sampled households using structured questionnaire, Focused Group Discussion (FGD), and key informant interview. Secondary data have been collected from published and unpublished documents. Descriptive statistics and logistic regression have been used as method of data analysis using STATA software, version 12.

\section{Specification of Econometric Model}

Following Gujarati [9], the logistic probability function for out-migration is defined as

$$
P i=\frac{1}{\left(1+e^{-z i}\right)} .
$$

For ease of exposition, (1) is rewritten as

$$
P i=\frac{1}{1+e^{-z i}}=\frac{e^{z i}}{e^{-z i}} .
$$

As shown above, if $P i$ is the household probability to be involved in out-migration and the probability of households not to be involved in migration, that is, $1-P i$, is given as follows

$$
1-P i=\frac{1}{1+e^{z i}}
$$




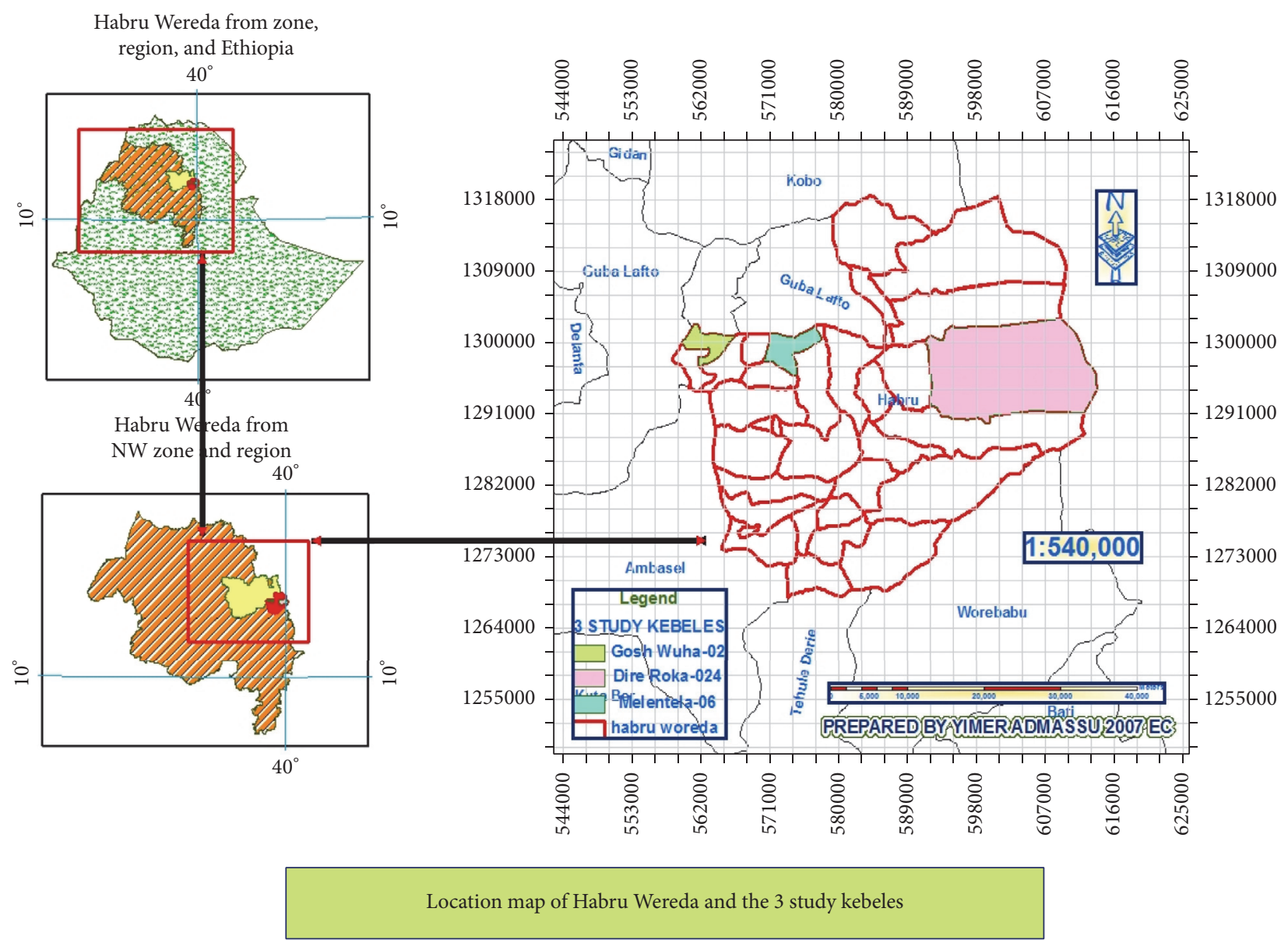

FIgURE 2: Map of the study area. (C) GIS sketch by Yimer Admassu, 2015.

therefore,

$$
\frac{P i}{1-P i}=\frac{1+e^{z i}}{1+e^{-z i}}=e^{z}
$$

Hence, $P i /(1-P i)$ is the ratio of a probability that a household is involved in out-migration to probability that a household is not involved in migration. Taking the natural logarithms of the odds ratio, the logistic regression model out-migration is a function of several push-pull determinant factors given as follows:

$$
\begin{aligned}
\ln \left(\frac{P i}{1-P i}\right)= & Z i \\
= & \beta_{0}+\beta_{1} \mathrm{AGE}+\beta_{2} \mathrm{SEX}+\beta_{3} \mathrm{FAMSZ} \\
& +\beta_{4} \mathrm{ACCCR}+\beta_{5} \mathrm{REAS}+\beta_{6} \mathrm{LHS} \\
& +\beta_{7} \mathrm{LIVE}+\beta_{8} \mathrm{CONFL} \\
& +\beta_{9} \text { PESTINFE }+\beta_{10} \mathrm{DROU} \\
& +\beta_{11} \mathrm{ACCINFON}+e_{\mathrm{mig}},
\end{aligned}
$$

where $Z i$ is a probability of migration against nonmigration, ranging from 0 to 1 . Rural out-migration is the dependent variable. A household is considered as migrant sending if it has at least one migrant member.
AGE (Age of the Household Head in Years). It is hypothesized that the younger the age of the head, the higher the propensity for migration.

SEX (Sex of the Household Head; 0 Is Male and 1 Is Female). It is hypothesized that females are more migratory than males.

FAMSZ (Number of Family Members in the Household). It is hypothesized that larger sized households have higher number of individuals migrating internally or internationally.

ACCR (Access to Credit). It is equal to 1 if household has access to credit and 0 otherwise. Migration is among the strategies to acquire capital. It is hypothesized that households with access to credit have lower inclination to migrate.

REAS (Relief Assistance). It is equal to 1 if household has access to relief assistance and 0 otherwise. It is hypothesized that migration is one of the strategies to reduce vulnerability and maximize income in emergencies or crises. Thus, access to relief assistance can influence decision for migration. Households who received relief assistance have lower probability to migrate.

LHS (Land Holding Size in Hectares). Land is an indicator of wealth. It is hypothesized that the larger the size of land holding, the lower the chance of migration. 
TABLE 1: Household characteristics of respondents $(n=200)$.

\begin{tabular}{|c|c|c|}
\hline Household characteristics & Frequency & Percentage \\
\hline \multicolumn{3}{|l|}{ Migration status of households } \\
\hline Migrant sending households & 76 & 38 \\
\hline Nonmigrant sending households & 124 & 62 \\
\hline \multicolumn{3}{|l|}{ Household migrants' number } \\
\hline Households with no migrant members & 124 & 62 \\
\hline Households with one migrant member & 46 & 23 \\
\hline Households with two migrant members & 27 & 13.5 \\
\hline Households with three migrant members & 3 & 1.5 \\
\hline \multicolumn{3}{|l|}{ Age of migrants household members } \\
\hline Nonmigrants & 124 & 62 \\
\hline $15-24$ years & 48 & 24 \\
\hline $25-34$ years & 23 & 11.5 \\
\hline $35-64$ years & 5 & 2.5 \\
\hline \multicolumn{3}{|l|}{ Sex of respondents } \\
\hline Female & 28 & 14 \\
\hline Male & 172 & 86 \\
\hline \multicolumn{3}{|l|}{ Households and sex of their migrant household members } \\
\hline Households with no migrants & 124 & 62 \\
\hline Households with female migrants & 40 & 20 \\
\hline Households with male migrants & 22 & 11 \\
\hline Households with both female and male migrants & 14 & 7 \\
\hline \multicolumn{3}{|l|}{ Educational status } \\
\hline Unable to read and write & 78 & 39 \\
\hline Able to read and write & 122 & 61 \\
\hline \multicolumn{3}{|l|}{ Marital status } \\
\hline Unmarried & 0 & 0 \\
\hline Married & 200 & 100 \\
\hline
\end{tabular}

Source: authors' own computation from survey (2015).

LIVE (Livestock Ownership in Total Livestock Units). Livestock is an indicator of wealth and it is hypothesized that the more livestock the household has, the lower the mobility of households from their place of origin is.

CONFL (Conflict). It is equal to 1 if the household lives in conflict prone area and 0 otherwise. It is hypothesized that conflict is one of the push factors for migration decision.

PESTINFE (Pest Infestation). It is equal to 1 if there exists pest infestation and a household is vulnerable to it and 0 otherwise. The higher infestation of pest means the higher the probability of being food insecure and thus higher chance of migration and a livelihood diversification strategy.

DROU (Drought). It is equal to 1 if a household is vulnerable for drought and 0 otherwise. It is hypothesized that the existence of drought and the vulnerability of the household to drought is one of the push factors for migration.

ACCINFON (Access to Information and Networks). It is equal to 1 if household has access to information and 0 otherwise. It is hypothesized that the presence of access to information increases the probability of migration.

\section{Results and Discussion}

6.1. Sociodemographic Characteristics and Determinants of Rural Out-Migration. Rural out-migration is a common practice and coping strategy for rural families in Ethiopia in general and in Habru district in particular. The following paragraphs depict the descriptive analysis of the sociodemographic variables followed by logistic analysis result of some determinant variables of rural out-migration in the study area.

6.1.1. Sex of Household Head. Out of the total of 200 sampled respondents, 172 households $(86.0 \%)$ were males whereas the remaining 28 households $(14.0 \%)$ were female respondents (as indicated in Table 1). Among the migrating household members, about $53 \%$ are females depicting that more female household members are migrating more than the males. Gender affects diversification options, including the choice of income-generating activities (both farm and nonfarm) due to culturally defined roles, social mobility limitations, and differential ownership of/access to assets. The logistic regression analysis results showed that females are more migratory than their male counterparts. As expected, being a male household head is found to reduce the likelihood 
TABLE 2: Logistic regression analysis result of determinant factors for rural out-migration in the study area $(n=200)$.

\begin{tabular}{|c|c|c|c|c|}
\hline Determinant factors & Odds ratio & Standard error & $Z$ & $P>|Z|$ \\
\hline Sex & 0.253 & 0.208 & -1.67 & $0.095^{* *}$ \\
\hline Age & 2.181 & 1.603 & 1.06 & 0.289 \\
\hline Family size & 1.758 & 0.309 & 3.21 & $0.001^{* * *}$ \\
\hline Relief assistance & 3.480 & 2.287 & 1.90 & $0.058^{* *}$ \\
\hline Livestock ownership & 0.415 & 0.085 & -4.30 & $0.000^{* * *}$ \\
\hline Farm size & 0.0155 & 0.017 & -3.77 & $0.000^{* * *}$ \\
\hline Drought & 741.442 & 1.536 & 0.34 & 0.731 \\
\hline Intravillage conflict & 7.003 & 6.055 & 2.25 & $0.0241^{* *}$ \\
\hline Pest infestation & 1.106 & 0.628 & 0.18 & 0.859 \\
\hline Access to information & 177.110 & 269.693 & 3.4 & $0.001^{* * *}$ \\
\hline Access to credit & 0.957 & 0.556 & -0.08 & 0.940 \\
\hline \multicolumn{5}{|c|}{ Dependent variable: rural-out migration } \\
\hline \multicolumn{5}{|l|}{ Number of obs. $=200$} \\
\hline \multicolumn{5}{|l|}{ Prob $>$ chi $2=0.0000$} \\
\hline \multicolumn{5}{|l|}{ Pseudo $R 2=0.6340$} \\
\hline \multicolumn{5}{|l|}{ LR chi2 $(12)=168.41$} \\
\hline Log likelihood $=-4 \varepsilon$ & & & & \\
\hline
\end{tabular}

$* *$ and $* * *$ refer to significance at $5 \%(P<0.05)$ and $1 \%(P<0.01)$, respectively.

Source: authors' own computation from survey (2015).

for out-migration by a factor of 0.253 (Table 2). One of the reasons is that female household members have been hired by different local and international institutions or sectors in certain jobs such as household maids and cafeteria custodian available internally or in international destination countries.

6.1.2. Age. The mean age of the respondents is 47 years, with a minimum of 26 and a maximum of 87 years, which indicate that the majority of population living in the study areas are in productive ages. Out of the total migrant members, $17.7 \%$ were between the ages of 15 and 24 years as shown in Table 1. Migrants with ages between 25 and 34 years and above 34 years account for $11.5 \%$ and $2.5 \%$ of the total migrants, respectively (as indicated in Table 1). The logistic regression analysis showed that age is insignificant in determining rural out-migration (as indicated in Table 2).

6.1.3. Family Size. It is the total number of family members who live under one roof (number of people living together and utilizing scarce resources together). Family is an important source of labour supply in the area. Family size for the respondents was a minimum of one and maximum of eleven household members which is similar findings to [11]. The mean family size was 5.06 and the standard deviation was 2.08. The average household size has been 4.8 for Ethiopia and 4.33 for Amhara regional state (as shown in Table 1). As hypothesized, larger sized households have positive effect on raising the flow of migration internally or externally. Since labour is the main input in crop production, larger households face fewer labour bottlenecks at critical points in the farming cycle such as land preparation and harvest time. Thus, family size is hypothesized to determine migration positively in one or other ways. Results show that there is positive association between migration of family members and size of family. As the size of family increased the per capita income of the household decreased and the household faced the problems of livelihood. Therefore, the family members had to migrate in search of a job in urban areas. The odds ratio value in Table 1 indicated that, with oneunit increase in family size, the probability of migration of family members increased by a factor of 0.016 .

6.1.4. Relief Assistance. The number of landless people is increasing, and land degradation is common in Northeast part of Amhara region in general. Habru is one of the districts in the region where both chronic and transitory food insecurity are persistent problems. A substantial number of households are chronically food insecure, and they are not able to produce enough for their subsistence even in years of normal rainfall. As a result, food aid through productive safety net program and direct food assistance has become an institutional feature. Poverty is widespread in both rural and urban areas. However, the magnitude is greater in drought-prone rural areas like the case of Habru district. The household food sufficiency is also commonly used variably to measure the level of living. In this regard, rural respondents were asked to report if their household is food sufficient throughout all the seasons. Accordingly, only 108 (54\%) of the households were found to be food secured, while the bulk of the households 92 (46\%) were falling in the food insecure category. This shows that most of the communities are forced to move from their origin to find different alternatives livelihoods for them or their families. Similarly those who got the relief assistance households were 102 (51\%) and the remaining 98 (49\%) have not got the relief assistance for the last five years. This indicate that almost $50 \%$ the communities are not addressed by relief assistance especially for those who need emergency assistance to cope with different shocks. 
Actual correlations between food assistance and migration are rarely completely causal; a host of other factors influences people's decisions about where and when to move. Migration can be one of a number of strategies to reduce vulnerability and maximize income in anticipation of emergencies or crises. Households or individuals may decide to migrate to areas where they expect, on the basis of past experience or information circulating at the moment. People may also decide to migrate to places where they believe that there will be greater protection, safety, and security. These issues are usually as significant as, if not more so than, the availability of material assistance. Access to food assistance or other forms of assistance is seldom, the only determinant in people's decisions about where to move during crises. Relief assistant was found to influence rural out-migration positively. A unit increase in relief assistance has increased the likelihood of rural out-migration by a factor of 3.48 (as indicated in Table 1). This shows that the poorer households are supported by relief assistance and those households are more migratory than better-off households.

6.1.5. Total Livestock Units (TLU). Most household heads have livestock with the minimum of 0 and maximum of 13.71, with mean of 5.22 and standard deviation of 3.79 . The average livestock size of the households has less total livestock units than the findings by Eshetu [12] conducted at another district of North Wollo, that is, Gubalfto district. Livestock ownership is a continuous variable and measured in TLU (Tropical Livestock Unit). Unlike urban dwellers, the rural households accumulate their wealth in terms of livestock. They are prominent sources of wealth to farm households and supply manure to improve soil fertility. Households with large livestock size are expected to be less vulnerable to food insecurity especially in times of drought when crops fail to yield [13]. Therefore, possession of large size of livestock increases the likelihood of the household to be food secure; and therefore livestock are one of the major sources of income in rural areas. This is true in areas where mixed farming is practiced particularly where the ownership of farm oxen forms the cornerstone of farm economy in the rural households. Livestock ownership determines the household's food security status and the level of vulnerability to different migration internally or internationally. It was hypothesized that more livestock was negatively related to mobility of the community from their normal residence. The variable is used as proxy for wealth, farmers with more livestock units, which can readily be converted to money and the ability to purchase different food and nonfood items necessary to the household members compared to those that own fewer livestock units. Moreover, families with more animals are less likely to have larger movement of household members than those with fewer animals. The logistic analysis result in Table 2 indicated that a unit increase in TLU leads to reduction of the probability of rural out-migration by a factor of 0.415 . The result is in line with the findings of Beyene and Muche [13] depicting that households with large livestock size are found to be to be less vulnerable to food insecurity especially in times of drought when crops fail to yield. Therefore, possession of large size of livestock increases the likelihood of the household to be food secure and reduces the probability of rural out-migration.

6.1.6. Farm Size. Land is a basic asset of people's livelihoods in rural areas of Amhara region in general and the study area in particular. The number of population has been increasing and thus the average landholding and its productivity are decreasing from time to time. In addition to the decline of land productivity due to reduction of the fertility of the soil, other natural shocks such as drought, pest infestation, and scarcity of farmland are important factors of out-migration of rural people seeking for wage and related employment opportunities. About 7\% of respondents have no farm land at all, 38.5\% have a hectare of land, $1.5 \%$ have 2 hectares, and the majority have below 1 hectare of land. This shows that most household heads have small plots of land (below 1 hectare) that have not been enough to feed the total household member or their family, thus leading to both seasonal and permanent migration in order to secure the household food security situation. The size of land cultivated, as a basic input in farming, is significantly associated with food security status of a household. Land in this district serves as means of coping mechanism during serious food shortage and collateral to receive credit service. This means households with large cultivated land produce more for household consumption and sale and have better chance to be food secure than those having relatively small size of cultivated land. The odds ratio for this variable (as shown in Table 2) indicates that, maintaining other determinants constant, additional unit of cultivated land will reduce the probability of rural out-migration by factor of 0.016 . The result is in line with the findings of Beyene and Muche [13] indicating that households with large cultivated land are less likely to be food insecure and vice versa which is the same to migration of the household to move elsewhere to fill the gap of food insecurity for themselves or their families.

6.1.7. Drought. Most of respondents (95.16\%) replied that drought is the factor that determines the mobility of rural households while the rest $(4.83 \%)$ did not list the major determinant factors of seasonal and/or permanent migration. Among migrated household heads, $97.4 \%$ of them replied that drought is one of the factors that aggravate migration of individuals while the rest of households explained that drought is not among the factors that force moving the communities from their place of origin. However, drought has been found to have insignificant effect in terms of determining rural out-migration in the logistic regression analysis result.

6.1.8. Intravillage Conflict. From the total of 200 respondent in study areas $163(81.5 \%)$ of them responded that conflict is not a reason for out-migration while the rest of 37 (18.5\%) replied that conflict is one of the causes that restrict production in the study area. Intravillage conflict is one of the determinant factors that affect the movement of the community from one place to the other in search of different livelihood strategies. This is due to the fact that rural households not having favorable condition to live are involved 
in different farm and nonfarm livelihood alternatives to secure themselves and their families. The result shows that an increase in the incidence of village conflict increases the likelihood of rural out-migration by a factor of 7 (as indicated in Table 2). De Waal [14] found out that the effects of conflict and poverty issues on migration patterns are considerable. Moreover, conflicts in Ethiopia severely damaged agricultural capital, thereby hindering agricultural practices. This, in turn, led to poverty, which caused large migration movements of people seeking better living conditions elsewhere.

6.1.9. Pest Infestation. Insect and pest infestations are important biological factors restraining crop production and cause food deficit. Therefore insect and pest infestations have negative correlations with food security status and had been directly related to the movement of people from place to place to ensure household food security situation. 79 (39.5\%) of the households explained that pest infestation is one of the determinant factors that aggravate movement of people from place to place in order to search for food security related strategies for them or their families. The logistic regression analysis showed that pest infestation has insignificant effect in determining rural out-migration.

6.1.10. Access to Credit Services. Access to basic services such as credit provided by governmental or a nongovernmental organization is decisive and crucial to improve productivity and improve the livelihood of poor rural households. Access to credit is one of the alternative livelihood strategies in the rural households of Amhara region in general and the study areas in particular. Credit, be it formal or informal, is an important source of purchasing inputs for agricultural activities in the rural economy. Credit availability promotes income diversification, which in turn reduces seasonal and permanent migration. However, only about 38 (19.74\%) and $23(30.26 \%)$ of the sample households who have nonmigrated and migrated household head, respectively, received credit. The main sources of credit in the study areas were Amhara credit and service institution and different cooperatives implemented by government structures. However, the logistic regression analysis showed that access to credit has insignificant effect in determining rural out-migration in the study area keeping other variables constant.

6.1.11. Access to Information and Networks. Information flow and personal networks such as friendship and kinship connections are important determinants of migration in the study area. Almost all of migrants have earlier information and networks about the destination area before migration. The sources of information are friends and relatives living in the destination regions as well as returnees. The results in Table 2 indicated that a unit increase in access to information and networks increases the probability of rural out-migration by a factor of 177 .

\section{Concluding Remarks}

Rural out-migration has been an important issue for policy makers and governments in developing countries, particularly in sub-Saharan Africa. Rural out-migration has resulted in drastic decrease in the labour force on one hand and increase in income of migrant sending households on the other hand. Many studies found out that the push factors are the major determinants for causing rural out-migration in the least developed economies. The flow of information and social networks also play an important role in determining migrants' specific place of destination and their works. Most of the migrants are not satisfied with their current employment because of the reason of its less security, mismatch of their expectation, and other different reasons. Migrants have been also misinformed about employment opportunities and income in destination areas. What migrants heard about the job and income in the destination region has been unreliable. Besides the transmission of false information, the presence of their friends, relatives, and family members at destination region has given the confidence for the migrants to make spontaneous decision to migrate. Taking into account the findings of the study and the current status of rural outmigration in the study area, the following recommendations are forwarded:

(i) Rural out-migration can have a positive impact on livelihoods of households through the flow of remittances and reducing pressure on land in the origin area. Therefore, migration needs to be managed well. In this regard, establishment of ICT centers in the rural areas, local media, and information centers have a paramount importance in providing reliable information and opportunities about destination areas. This helps to minimize exaggerated information and unnecessary expectations about destination regions.

(ii) Rural development strategy through rural livelihood intensification and diversification of agriculture is important to reduce rural harsh conditions confronted by the youth in the origin area.

(iii) Vocational training of the rural people on small scale industries and nonfarm job opportunities that could generate alternative income for rural households should be introduced in rural areas. This will minimize the problem of landlessness and land shortage and their total dependency on only one source of livelihood, especially agriculture related production.

(iv) Development of small scale irrigation alleviates the problem of rain fed dependence cultivation system and is used to produce additional food and cash oriented crops.

\section{Conflicts of Interest}

The authors declare that there are no conflicts of interest regarding the publication of this paper.

\section{References}

[1] A. Bariagaber, Conflict and the Refugee Experience: Flight, Exile and Repatriation in the Horn of Africa, Ash gate Publishing, Farnham, UK, 2006. 
[2] W. Naude, "Determinants of migration from Sub-Saharan African Countries. World Institute for Development Economics Research, United Nations University," Journal of African Economies, vol. 19, no. 3, pp. 330-356, 2010.

[3] M. J. Greenwood, "Human migration: theory, models, and empirical studies," Journal of Regional Science, vol. 25, no. 4, pp. 521-544, 1985.

[4] E. Ivan, Internal Migration: A Review of the Literature, MPRA paper no. 8783, University of Cagliari, 2008.

[5] L. Marchiori, J. F. Maystadt, and I. Scumacher, "Another inconvenient truth: climate change and migration in Sub-Saharan Africa," in Proceedings of the Conference on the Transnationality of Migrants (TOM '10) Marie Curie Research Training Network 'International Migration: Transnational links, Effects and Policies', Venice International University, September 2010.

[6] S. Barrios, L. Bertinelli, and E. Strobl, "Climatic change and rural-urban migration: the case of Sub-Saharan Africa," Discussion Paper 2006/46, Belgian Program on Interuniversity Poles of Attraction, 2006.

[7] M. Brockerhoff and H. Eu, "Demographic and socioeconomic determinants of female rural to urban migration in sub-Saharan Africa," International Migration Review, vol. 27, no. 3, pp. 557$577,1993$.

[8] W. L. Neuman, Social Research Methods: Qualitative and Quantitative Approaches, Allyn and Bacon, Boston, Mass, USA, 2000.

[9] D. N. Gujarati, Basic Econometrics, The McGraw-Hill Companies, 4th edition, 2004.

[10] A. Ishtiaque and M. S. Ullah, "The influence of factors of migration on the migration status of rural-urban migrants in Dhaka, Bangladesh," Human Geographies, vol. 7, no. 2, pp. 4552, 2013.

[11] B. Gebru, Impact of male out migration on rural women livelihood, the case of Chencha woreda, South Ethiopia [M.A. thesis], Addis Ababa University, 2006.

[12] A. Eshetu, Impacts of Climate Variability and Change on Food Security and Farmers' Adaptation Strategies in Gubalfto Woreda, North Wollo, Ethiopia, 2011.

[13] F. Beyene and M. Muche, "Determinants of food security among rural households of central Ethiopia: an empirical analysis," Journal of International Agriculture, vol. 49, no. 4, pp. 299-318, 2010.

[14] A. De Waal, Evil Days: Thirty Years of War and Famine in Ethiopia, Human Rights Watch, 1991. 


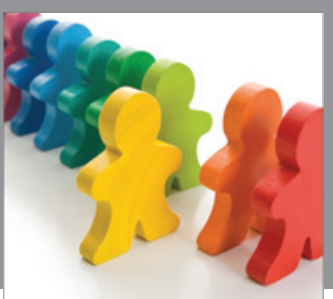

Autism

Research and Treatment
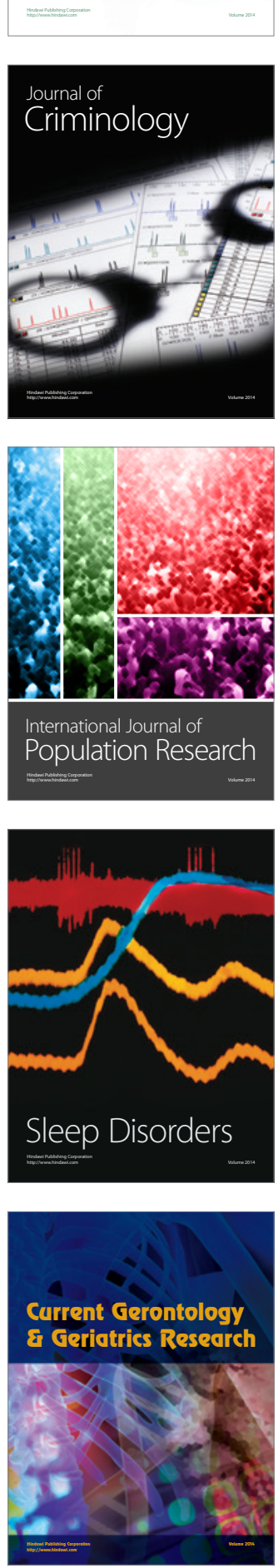

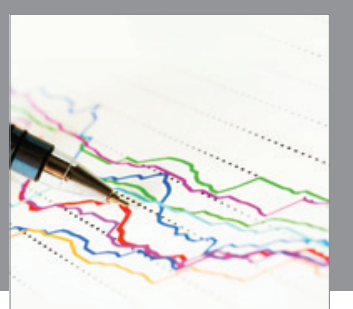

Economics

Research International
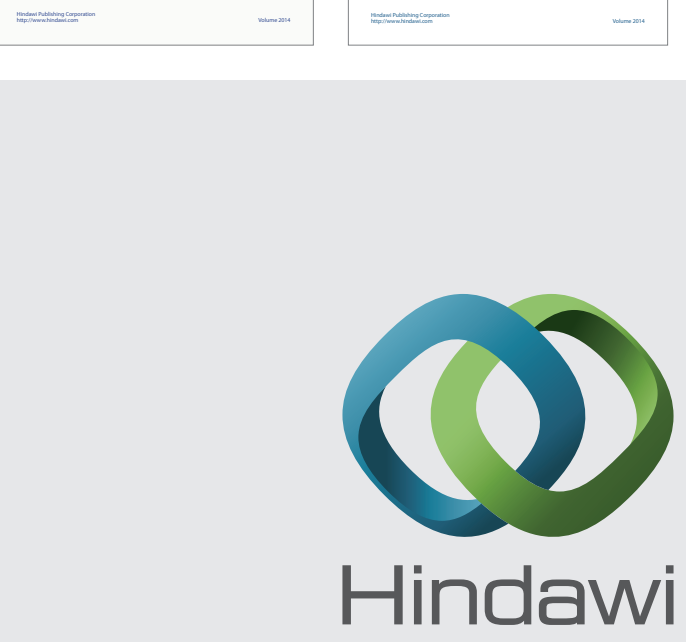

Submit your manuscripts at

https://www.hindawi.com
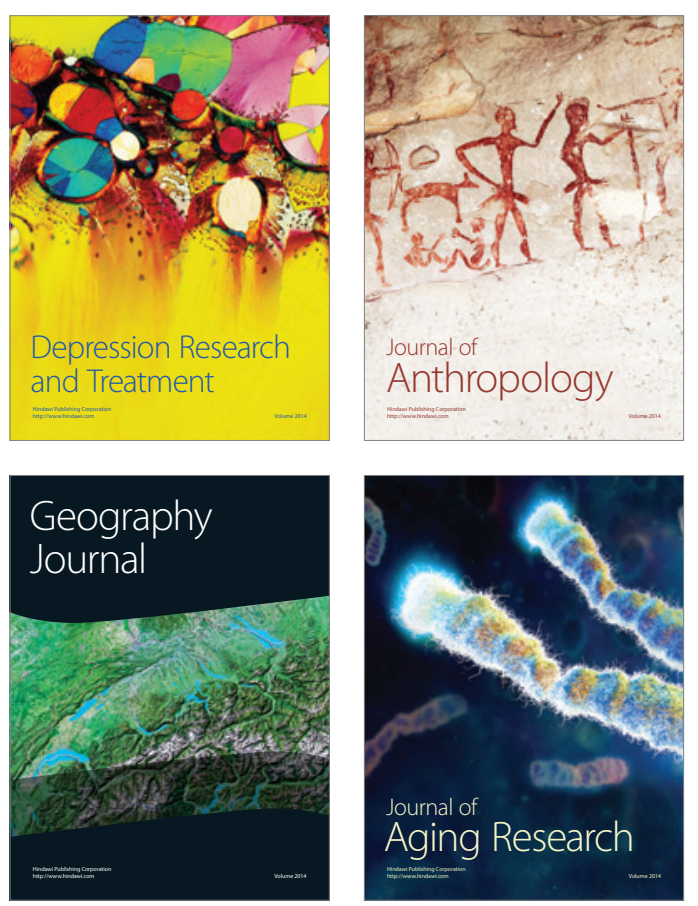
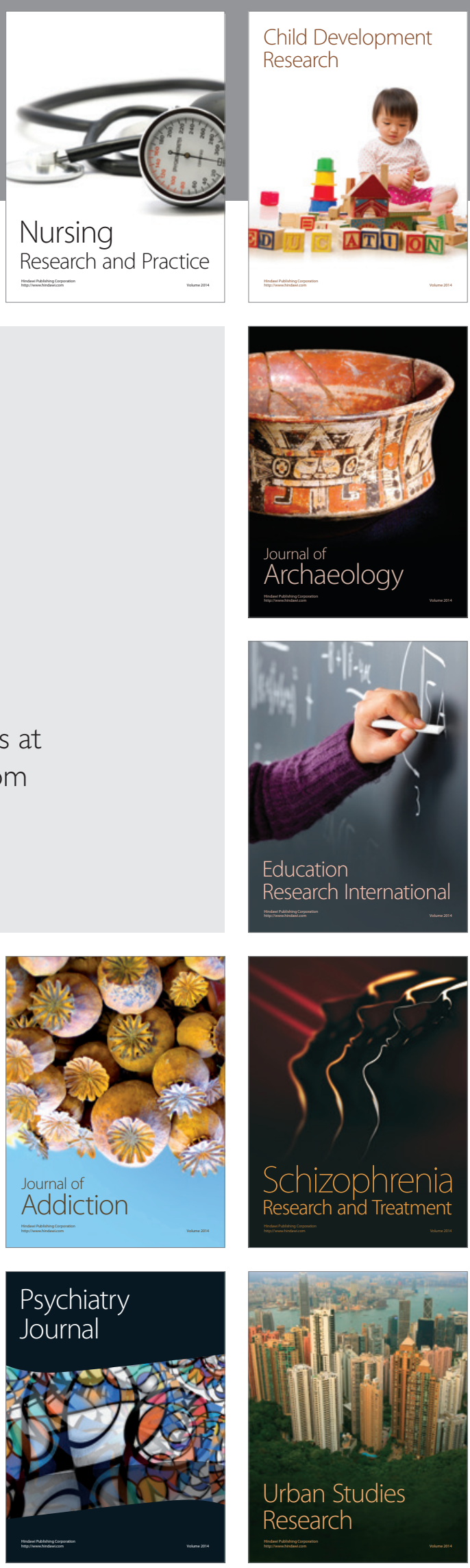